\title{
The role of IL-1 receptor type 1-mediated macrophage accumulation in adipose tissue: insights into the development of obesity-induced insulin resistance
}

\author{
K. A. Harford ${ }^{1}$, M. Claessens ${ }^{1}$, E. Oliver ${ }^{1}$, C. Reynolds ${ }^{1}$, K. H. G. Mills ${ }^{2}$ and H. M. Roche ${ }^{1}$ \\ ${ }^{1}$ Nutrigenomics Research Group, UCD Conway Institute, University College Dublin, Belfield, Republic of Ireland \\ and ${ }^{2}$ School of Biochemistry and Immunology, Trinity College Dublin, Republic of Ireland
}

\begin{abstract}
Macrophages are a heterogeneous population of cells that play a role in the innate immune response to infection. Recent studies have shown that macrophages are key cells in the development of obesity, wherein there is progressive infiltration of macrophages into the adipose tissue. These adipose tissue macrophages are referred to as classically-activated, or M1, macrophages ${ }^{(1)}$. They release proinflammatory cytokines such as IL-1, IL-6 and TNF $\alpha$ creating an inflammatory response that can contribute to insulin resistance and type 2 diabetes mellitus ${ }^{(2)}$. In lean individuals macrophages are in an M2-polarization, or alternatively-activated, state and are thought to protect against inflammation. The IL-1 receptor type 1 (IL-1R1) is responsible for transmitting the pro-inflammatory effects of IL-1. The aim of the present study was to determine the number of adipose tissue macrophages and their activation state using flow cytometry in wild type (WT) mice and in IL-1R1 ${ }^{-1-}$ mice at certain time points over a period of 16 weeks.

C57BL/6 WT and IL-1R1 $1^{-1-}$ mice with a C57BL/6 background (six to eight mice per group) were fed a high-fat diet (45\% energy from fat) for 16 weeks. At weeks 0,6 and 16 epididymal adipose tissue (EAT) and visceral adipose tissue (VAT) samples were taken from the C57BL/6 WT and IL-1R1 ${ }^{-1}$ mice. Adipocytes and stromal vascular cells (SVC) were isolated from the adipose tissue by collagenase treatment. SVC were labelled with antibodies for macrophage markers F4/80, CD11B and CD11C and analysed by flow cytometry to determine the number of macrophages and activation status of the macrophages present. Triple-positive cells $\left(\mathrm{F} 4 / 80^{+} \mathrm{CD}_{11 \mathrm{~B}}^{+} \mathrm{CD} 11 \mathrm{C}^{+}\right)$ are associated with the M1-polarization state, while double-positive cells $\left(\mathrm{F} 4 / 80^{+} \mathrm{CD} 11 \mathrm{~B}^{+} \mathrm{CD} 11 \mathrm{C}^{-}\right)$indicate $\mathrm{M} 2$ macrophages ${ }^{(3)}$.

At week 0 there was a significantly larger population of $\mathrm{F} 4 / 80^{+} \mathrm{CD}_{11 \mathrm{~B}^{+} \mathrm{CD}_{11 \mathrm{C}^{-}}(\mathrm{M} 2) \text { cells in the EAT and VAT of the IL-1R1 }}{ }^{\prime-}-$ group compared with the WT group $(P<0.05)$ but no difference between groups in the number of $\mathrm{F} 4 / 80^{+} \mathrm{CD} 11 \mathrm{~B}^{+} \mathrm{CD} 11 \mathrm{C}^{+}(\mathrm{M} 1)$ cells. However, after 6 weeks on a high-fat diet there was a larger population of the more active $\mathrm{F} 4 / 80^{+} \mathrm{CD} 11 \mathrm{~B}^{+} \mathrm{CD} 11 \mathrm{C}^{+}(\mathrm{M} 1)$ cells in the EAT of the WT group compared with the IL-1R $1^{-1-}$ group $(P<0.05)$ while there was a reduced number of $\mathrm{F} 4 / 80^{+} \mathrm{CD} 11 \mathrm{~B}^{+} \mathrm{CD} 11 \mathrm{C}{ }^{-}$ (M2) cells in the IL-1R1 ${ }^{-1-}$ group compared with week 0 . After 16 weeks on a high-fat diet there was no significant difference in the number of $\mathrm{F} 4 / 80^{+} \mathrm{CD} 11 \mathrm{~B}^{+} \mathrm{CD} 11 \mathrm{C}^{+}(\mathrm{M} 1)$ cells between the two groups of mice. Interestingly by week 16 there was a higher population of $\mathrm{F} 4 / 80^{+} \mathrm{CD}_{11 \mathrm{~B}}{ }^{+} \mathrm{CD} 11 \mathrm{C}^{-}(\mathrm{M} 2)$ cells in the EAT and VAT of the WT group compared with the IL-1R1 ${ }^{-/-}$group $(P<0.05)$.

These results imply that impairing IL-1 signalling decreases the macrophages ability to switch from an M2-polarization state to the proinflammatory M1-polarization state. This outcome delays the infiltration of M1 macrophages into the adipose tissue, thereby lowering the pro-inflammatory response and attenuating the progression of insulin resistance. Further studies are continuing in order to determine the molecular mechanisms by which this process occurs.
\end{abstract}

This project is funded by the SFI Principal Investigator programme awarded to H. M. R.

1. Lumeng CN, Bodzin JL \& Saltiel AR (2007) J Clin Invest 117, 175-184.

2. Weisburg SP, McCann D, Desai M et al. (2003) J Clin Invest 112, 1796-1808.

3. Nguyen AMT, Favelyukis S, Nguyen AK et al. (2007) J Biol Chem 282, 35279-35292. 